\title{
The auroral and ionospheric flow signatures of dual lobe reconnection
}

\author{
S. M. Imber ${ }^{1}$, S. E. Milan ${ }^{1}$, and B. Hubert ${ }^{2}$ \\ ${ }^{1}$ Department of Physics and Astronomy, University of Leicester, Leicester, UK \\ ${ }^{2}$ Institut d'Atmospherique et de Geophysique, Université de Liège, Liège, Belgium \\ Received: 13 February 2006 - Revised: 9 October 2006 - Accepted: 13 October 2006 - Published: 22 November 2006
}

\begin{abstract}
We present the first substantial evidence for the occurrence of dual lobe reconnection from ionospheric flows and auroral signatures. The process of dual lobe reconnection refers to an interplanetary magnetic field line reconnecting with lobe field lines in both the northern and southern hemispheres. Two bursts of sunward plasma flow across the noon portion of the open/closed field line boundary (OCB), indicating magnetic flux closure at the dayside, were observed in SuperDARN radar data during a period of strongly northward IMF. The OCB is identified from spacecraft, radar backscatter, and auroral observations. In order for dual lobe reconnection to take place, we estimate that the interplanetary magnetic field clock angle must be within $\pm 10^{\circ}$ of zero (North). The total flux crossing the OCB during each burst is small $(1.8 \%$ and $0.6 \%$ of the flux contained within the polar cap for the two flows). A brightening of the noon portion of the northern auroral oval was observed as the clock angle passed through zero, and is thought to be due to enhanced precipitating particle fluxes due to the occurrence of reconnection at two locations along the field line. The number of solar wind protons captured by the flux closure process was estimated to be $\sim 2.5 \times 10^{30}$ ( 4 tonnes by mass), sufficient to populate the cold, dense plasma sheet observed following this interval.
\end{abstract}

Keywords. Magnetospheric physics (Magnetospheric configuration and dynamics; Plasma convection; Solar windmagnetosphere interactions)

\section{Introduction}

When the interplanetary magnetic field (IMF) is directed southwards, i.e. has a component $B_{Z}<0$, magnetic reconnection takes place near the subsolar point of the magnetosphere where the IMF and the terrestrial magnetic field

Correspondence to: S. M. Imber

(si45@ion.le.ac.uk) are antiparallel (Fig. 1a). The addition of new open flux to the system by this process is responsible for the excitation of large-scale Dungey cycle (Dungey, 1961, 1963) flow in the magnetosphere and the twin-cell ionospheric convection pattern, driving most magnetospheric dynamic phenomena. This process is now relatively well understood (e.g. Cowley and Lockwood, 1992; Milan et al., 2003). In this paper we concentrate on the less well studied situation for northward IMF when lobe reconnection is thought to occur. We concentrate specifically on dual lobe reconnection which is postulated to occur when the East-West IMF component, $B_{Y}$, is near zero (Dungey, 1963). This process will be discussed in more detail in Sect. 1.2.

\subsection{Lobe reconnection}

During intervals of northward IMF $\left(B_{Z}>0\right)$ it is expected that lobe reconnection will occur (e.g. Dungey, 1963; Russell, 1972; Reiff and Burch, 1985; Milan et al., 2000). The IMF drapes over the magnetopause such that the orientation of the IMF is antiparallel to that of the open lobe field lines tailward of the cusp. Reconnection occurs between the interplanetary magnetic field line and the geomagnetic field line and in most cases the result is a field line with one footprint in the northern or southern hemisphere, and the other end draped around the subsolar magnetopause and into the IMF (Fig. 1b shows lobe reconnection in the northern hemisphere). A combination of the magnetic tension force on the bent field line and the flow of the solar wind past the Earth results in the footprint of the field line being dragged initially sunward. Since it has remained open however, it stays within the ionospheric polar cap (the region of open field lines within the auroral oval) and does not cross the open/closed field line boundary (OCB). The field line then slips around the side of the magnetosphere and is added to the magnetotail lobe. For northward IMF the flows are expected to form two "reverse" convection cells in the noon sector of the polar cap (Fig. 1b). The field line footprints form a dual-cell reverse convection pattern,

Published by Copernicus GmbH on behalf of the European Geosciences Union. 

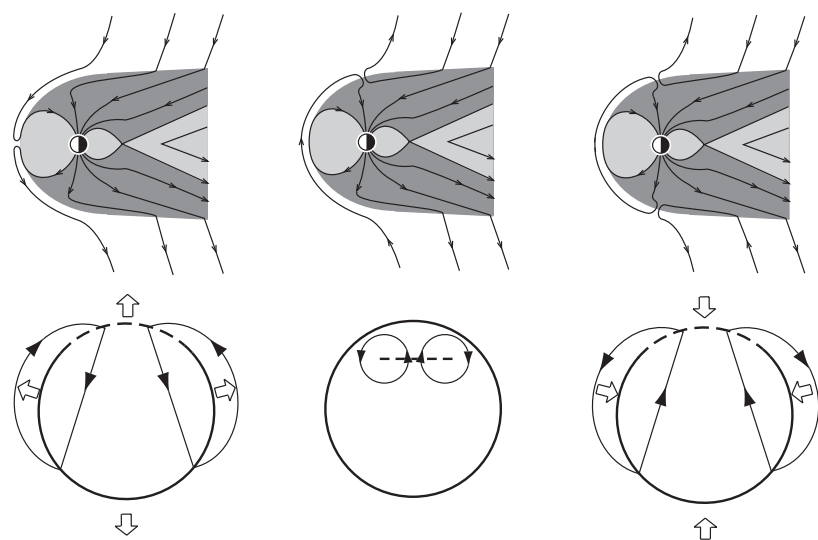

(b) Single lobe reconnection

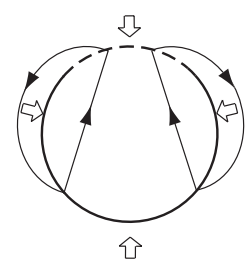

(c) Dual lobe reconnection

Fig. 1. Schematic representations of the magnetosphere in the GSM $\mathrm{X}-\mathrm{Z}$ plane and ionospheric convection patterns during single, low latitude and dual lobe reconnection. For the convection patterns the solid circle is the OCB, encircling the polar cap. The dashed portion of the OCB is the merging gap, the arrowed lines are flow streamlines and the large arrows indicate expansion or contraction of the polar cap. Local noon is directed towards the top of the figure.

where all flow is contained within the polar cap, with EastWest asymmetries introduced by the $B_{Y}$ component of the IMF (Cowley and Lockwood, 1992). The open flux of the polar cap that shares in the circulation is said to be "stirred" (Crooker, 1992).

The polar cap size is not expected to change during this process as no flux is being added to or removed from the polar cap, unlike, for instance the action of low latitude magnetopause reconnection which causes an expansion of the polar cap (Fig. 1a) (e.g. Siscoe and Huang 1985; Cowley and Lockwood, 1992; Milan et al., 2003).

Single lobe reconnection is expected to take place simultaneously, though independently, in both hemispheres when $B_{Y} \neq 0$. As will be described below we might expect the efficiency in either hemisphere to be affected by the dipole tilt and $B_{X}$ component of the IMF, the northern hemisphere being favoured for negative $B_{X}$ and northern hemisphere summer.

\subsection{Dual lobe reconnection}

The site of lobe reconnection on the magnetopause changes with the orientation of the IMF, Milan et al. (2000) having demonstrated a $B_{Y}$-dependence of the location of the lobe reconnection footprint in the ionosphere. This was recently confirmed with simultaneous measurements in both hemispheres by Østgaard et al. (2005). Similarly, the nature of the ionospheric flow associated with this process is distorted by $B_{Y}$ (Huang et al., 2000).

When $B_{Y}$ is non-zero, the displacement of the lobe reconnection sites in the northern and southern hemispheres means that different interplanetary magnetic field lines are recon- nected in the North and South - the two processes are independent of each other and we refer to this as single lobe reconnection occurring in the two hemispheres.

On the other hand, if $B_{Y}$ is close to zero it has been postulated that the same interplanetary magnetic field line can become reconnected in both hemispheres. This would result in a closed field line, ionospheric flow now crossing sunward across the dayside OCB and an associated contraction of the polar cap (Fig. 1c). Field lines that have been closed by this process will then be forced towards the tail by the solar wind pressure at the subsolar point. Figure 1c shows sunward flow across the dayside merging gap, representing the closure of field lines. The associated contraction of the polar cap leads to poleward flows around adiaroic portions of the $\mathrm{OCB}$, away from the merging gap.

Dual lobe reconnection is of interest not only in itself, but also because of its postulated role in the formation of a closed low latitude boundary layer and the population of a cold, dense plasma sheet during prolonged periods of northward IMF (e.g. Øieroset et al., 2005, and references therein). Following dual lobe reconnection, newly reconnected, closed field lines are located near the dayside magnetopause. These field lines contain a large amount of solar wind plasma that was captured during reconnection. This plasma is of solar wind origin and would therefore be cold (defined by Øieroset et al. (2005) as $<1 \mathrm{keV}$ ).

If the solar wind density was high enough and reconnection proceeded for enough time, it is thought that a sufficient number of particles would be captured to significantly enhance the plasma content of the magnetosphere. The pressure of the solar wind on the subsolar magnetopause then forces these newly reconnected field lines tailward, and it has been postulated that the addition of plasma on these field lines to the plasma sheet will lead to the formation of the cold, dense plasma sheet. The plasma sheet density is usually $\sim 0.3 \mathrm{~cm}^{-3}$, and Øieroset et al. (2005) define the threshold density for the cold, dense plasma sheet to be $1-2 \mathrm{~cm}^{-3}$. We will investigate the amount of plasma that could be captured by this process.

Dual lobe reconnection was first postulated by Dungey (1963) though it has not received much further attention as single lobe reconnection has been considered a more significant process (Cowley, 1981, 1983). A few studies have suggested that dual lobe reconnection could occur, and be significant as a plasma capture mechanism for the magnetosphere (e.g. Sandholt et al., 1999), though the evidence has been somewhat tenuous. This study describes the first attempt to identify the signatures of dual lobe reconnection from ionospheric flow measurements, to determine the occurrence and to quantify the significance of dual lobe reconnection for magnetospheric flux reconfiguration and transport. We use observations of the aurora with the IMAGE Far Ultraviolet Imager (FUV) (Mende et al., 2000a, b) to identify the OCB, supported by polar orbiting spacecraft particle measurements. The SuperDARN radar 

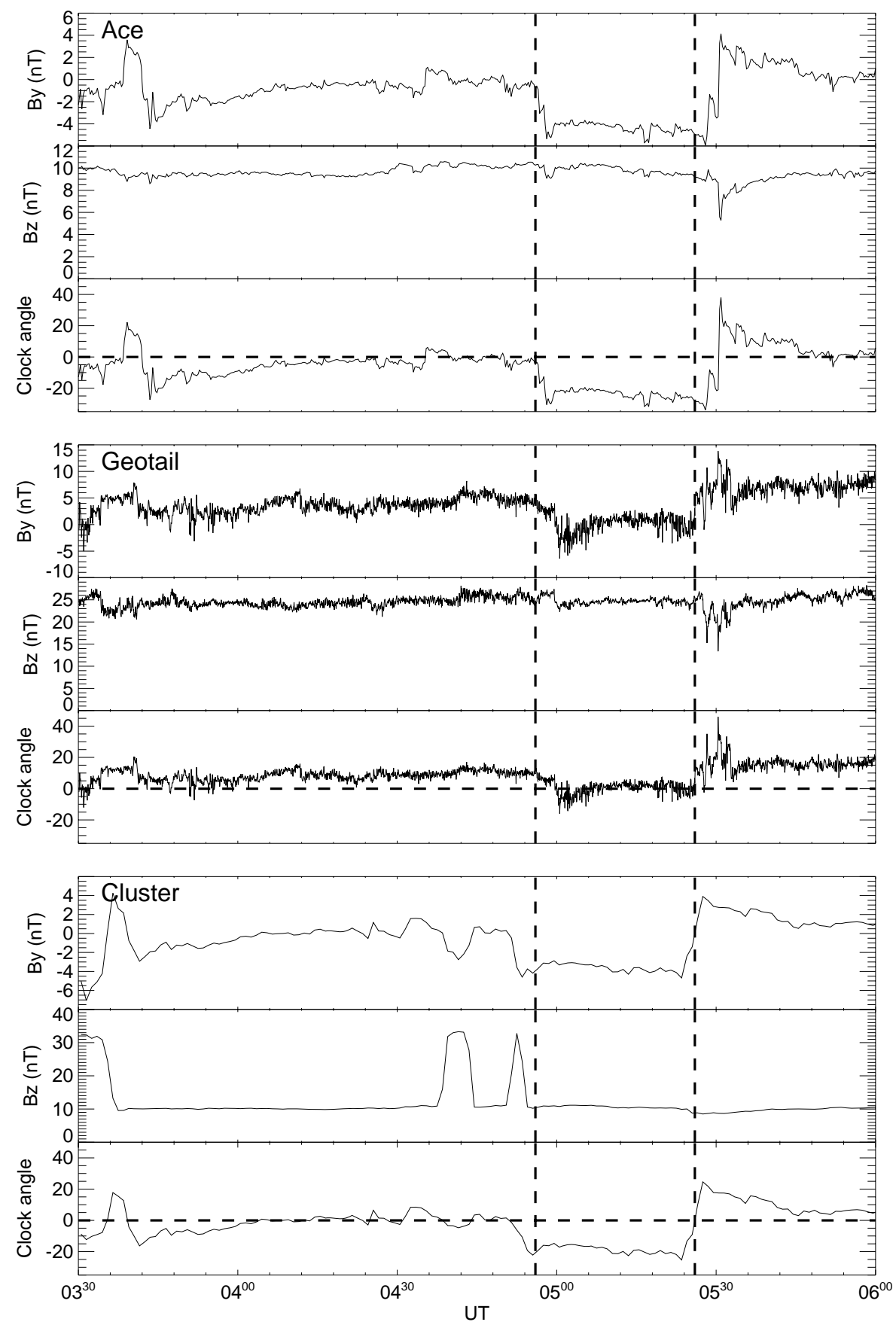

Fig. 2. GSM $B_{Y}$ and $B_{Z}$ interplanetary magnetic field components along with the corresponding clock angle, measured by ACE in the solar wind and Geotail and Cluster-3 within the magnetosheath, 03:30-06:00 UT on 18 December 2002. Vertical lines mark the average time that the clock angle passed through zero at Cluster and Geotail.

network (Greenwald et al., 1995) provides the ionospheric flow measurements, while upstream measurements of the solar wind and IMF are provided by ACE (Stone et al., 1998; Smith et al., 1998; McComas et al., 1998), Cluster (Balogh et al., 1997, Escoubet et al., 2001), and Geotail (Kokubun et al., 1994). The SOPA instruments on four of the LANL spacecraft (Belian et al., 1992) are employed to monitor the plasma sheet density for the interval surrounding the occurrence of dual lobe reconnection. 


\section{Observations}

The interval of interest is 03:30-06:00 UT on 18 December 2002. This period of continuous imaging of the northern hemisphere by the IMAGE FUV instrument was chosen because the IMF was strongly northward throughout, and the clock angle was observed to pass through zero several times (Fig. 2). In addition to this the coverage of the northern polar region by SuperDARN was good, and there were several spacecraft passing over the northern polar cap during the interval. Finally, it has been speculated that dual lobe reconnection may have been occurring at this time and was responsible for the population of a cold, dense plasma sheet (J. P. McFadden, private communication).

\subsection{IMF conditions}

It is important to accurately determine the IMF clock angle during the interval as this should give an indication of the times that dual lobe reconnection might be expected to occur. The clock angle is the angle made by the IMF to North in the GSM Y-Z plane, $0^{\circ}$ indicating a northwards orientation, $+90^{\circ}\left(-90^{\circ}\right)$ an eastwards (westwards) orientation, and $180^{\circ}$ southwards.

$\theta=\left\{\begin{aligned} \tan ^{-1}\left(B_{Y} /\left|B_{Z}\right|\right) & B_{z}>0 \\ 180^{\circ}-\tan ^{-1}\left(B_{Y} /\left|B_{Z}\right|\right) & B_{z}<0 .\end{aligned}\right.$

The solar wind and IMF measurements were made by ACE which was located at GSM X=241, Y=8 and Z=11 $R_{E}$ during the interval; Cluster was in the magnetosheath, near the bowshock at GSM X=5.2, $\mathrm{Y}=18.4, \mathrm{Z}=-2.4 R_{E}$; and Geotail was in the magnetosheath at GSM X=-8.0, Y=-22.0, $\mathrm{Z}=4.3 R_{E}$. A propagation delay of $65 \mathrm{~min}$ was added to the ACE data, based on a solar wind velocity of $V_{X}=-$ $380 \mathrm{~km} \mathrm{~s}^{-1}$. This delay does not take into account the slowing of the solar wind as it crosses the bowshock, introducing some uncertainty into the timing of the ACE clock angle. The GSM $B_{Y}$ component was approximately $0 \mathrm{nT}$ for most of the interval, falling to $-6 \mathrm{nT}$ at 05:00-05:30 UT. The GSM $B_{Z}$ component was close to $10 \mathrm{nT}$ throughout although it dropped very briefly to $5 \mathrm{nT}$ at $05: 30 \mathrm{UT}$. The GSM $B_{X}$ component remained constant at approximately $5 \mathrm{nT}$ throughout the interval.

The GSM $B_{Z}$ component of the IMF measured by Geotail was observed to be approximately $25 \mathrm{nT}$ throughout the interval, elevated above the ACE measurements due to compression of the solar wind as it crossed the bowshock. The GSM $B_{Y}$ component was around $5 \mathrm{nT}$ at the start of the interval, falling to around $-5 \mathrm{nT}$ at 05:00 UT and recovering to approximately $7 \mathrm{nT}$ at 05:30 UT. The GSM $B_{X}$ component was approximately constant at $5 \mathrm{nT}$, briefly falling to $-3 \mathrm{nT}$ between 05:00 UT and 05:30 UT. The differences between the Geotail and Cluster $B_{Y}$ magnetic field measurements could be due to field line draping, as Geotail is located $8 R_{E}$ downstream of the Earth.
Despite the passage of the solar wind and IMF through the bowshock and the compression of the plasma, the clock angle variation of the magnetosheath field was very similar to that of ACE, though rotated clockwise (when looking from the Sun) by $\sim 10^{\circ}$. This indicates that there is some uncertainty in the clock angle of the field near the lobe reconnection sites. This will be discussed more fully below.

Cluster was just outside the bowshock for much of the interval, and made very similar measurements to ACE. Brief enhancements in the field strength around 04:45 UT and 04:53 UT, most noticeable in $B_{Z}$, were due to excursions of the bowshock outwards, over the spacecraft, which correspondingly entered the magnetosheath. A comparison of the magnetic signatures seen at ACE and Cluster indicate that an ACE lag of approximately $60 \mathrm{~min}$ may have been more accurate.

At all three spacecraft the clock angle showed a very similar variation, with a sudden anticlockwise rotation of the IMF (when viewed from the Sun) of $\sim 20^{\circ}$ at 04:56 UT, followed by a clockwise rotation by $\sim 20^{\circ}$ at 05:28 UT, both indicated by vertical dashed lines in Fig. 2. Although the variations are the same, there are offsets at each spacecraft due to their spatial separation. As will be discussed below, we believe that two bursts of dual lobe reconnection occurred at the times of these rotations, possibly suggesting that the clock angle at the lobe reconnection sites went through $0^{\circ}$ at each turn.

Cluster and Geotail were both in the magnetosheath, Cluster near the bowshock and Geotail near the magnetopause, $8 R_{E}$ downstream of the Earth. There was a delay of a few minutes between seeing clock angle changes at Cluster and Geotail, which we assume was due to propagation delays within the slowed magnetosheath flow. Since neither of these spacecraft was exactly at the reconnection site, we have initially taken the times of the clock angle rotations to be half way between that recorded at Geotail and that recorded at Cluster. We estimate a \pm 4 min uncertainty in the time that the clock angle first passed through $0^{\circ}$.

\subsection{Image}

The IMAGE spacecraft was located over the northern polar cap throughout the interval, 03:30-06:00 UT on 18 December 2002. Images were taken approximately every $2 \mathrm{~min}$ using the Wideband Imaging Camera (WIC) and Spectrographic Imager instruments (Mende et al., 2000a, b). The WIC instrument operates in the far UV and has a spectral range of $140-160 \mathrm{~nm}$ with a field of view of $17 \times 17^{\circ}$. One channel of the Spectrographic Imager, SI12, is designed to image the proton aurora and therefore measures the Dopplershifted Lyman $\mathrm{H}$-alpha line at $121.82 \mathrm{~nm}$. Its field of view is $15 \times 15^{\circ}$. The other channel (SI13) measures electrons, concentrating on the oxygen $135.6 \mathrm{~nm}$ transition induced by electron impact.

These images were plotted on a geomagnetic polar grid as presented in Fig. 3. A typical image from $\sim 05: 03$ UT is 

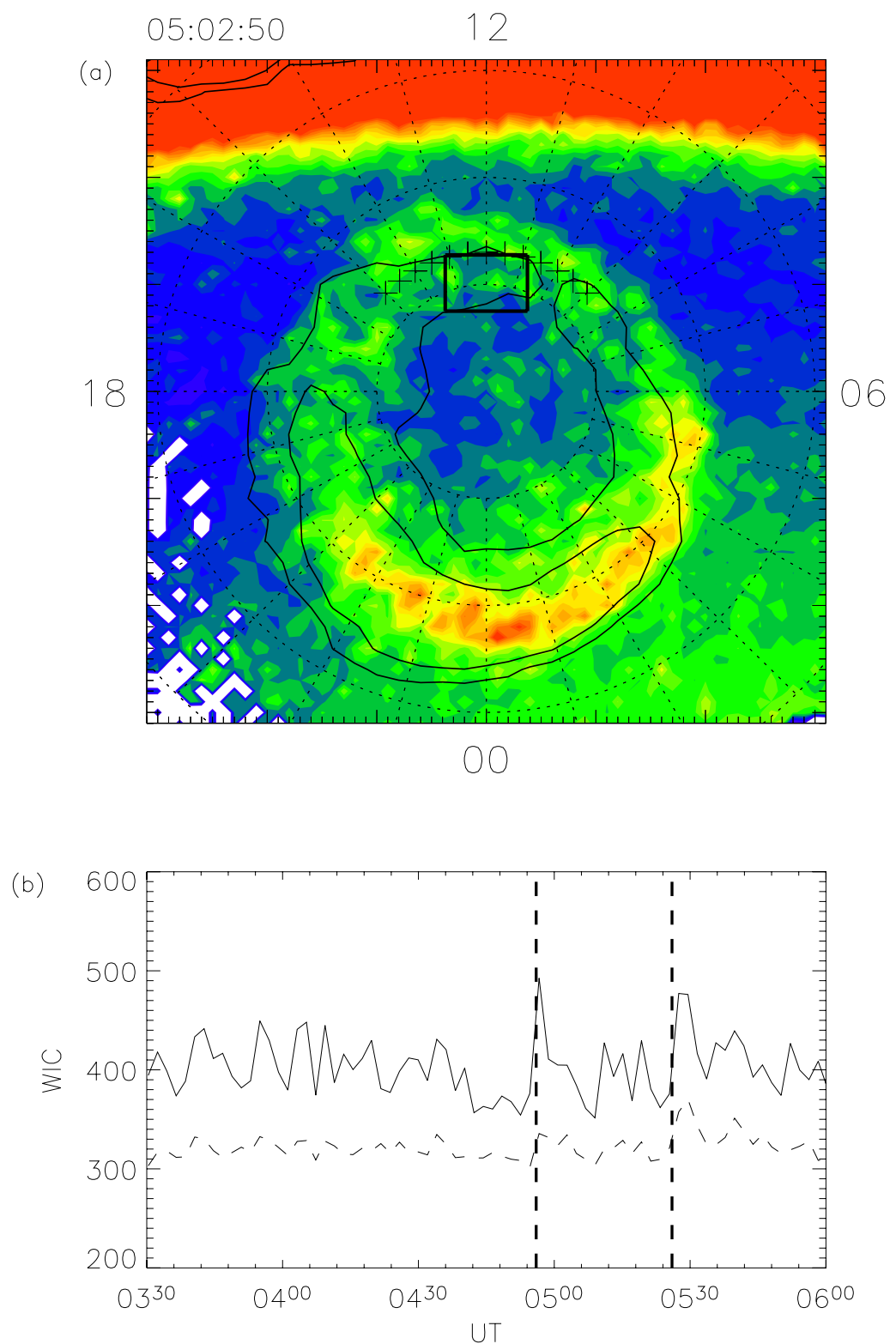

Fig. 3. (a) A typical image of the northern polar cap from the WIC instrument on the IMAGE spacecraft, 05:02:50 UT on 18 December 2002. The black square outline represents the area used to observe the change in brightness of the dayside aurora with time. The contours are the superposition of the intensity of the corresponding SI12 image, demonstrating that the proton aurora appear at higher latitudes than the electron aurora on the dayside. The location of the OCB is marked by black crosses between 09:00 and 15:00 MLT. (b) Maximum (solid line) and mean (dashed line) brightness of a small section of the WIC images. The vertical dashed lines represent the time that the clock angle passed through $0^{\circ}$, derived from the observations of ACE, Cluster and Geotail. The WIC image clearly shows an enhancement in the mean and maximum brightness just after the zero clock angle as measured by the spacecraft.

shown in a magnetic latitude and magnetic local time frame with 12:00 MLT at the top of the figure. Presented as a colour scale are the intensities measured by the WIC instrument. Dayglow is apparent at the top of the image. The auroral oval is clearly visible, with the presence of a relatively dim transpolar arc also evident. Superimposed on this as line contours is the intensity of the proton aurora measured by SI12. This demonstrates the relative locations of the electron and proton aurora. In most local time sectors the two are co-located, but near noon there is a clear offset, with the proton aurora displaced polewards of the electron aurora. As described below, we interpret the lower latitude region of electron aurora as 


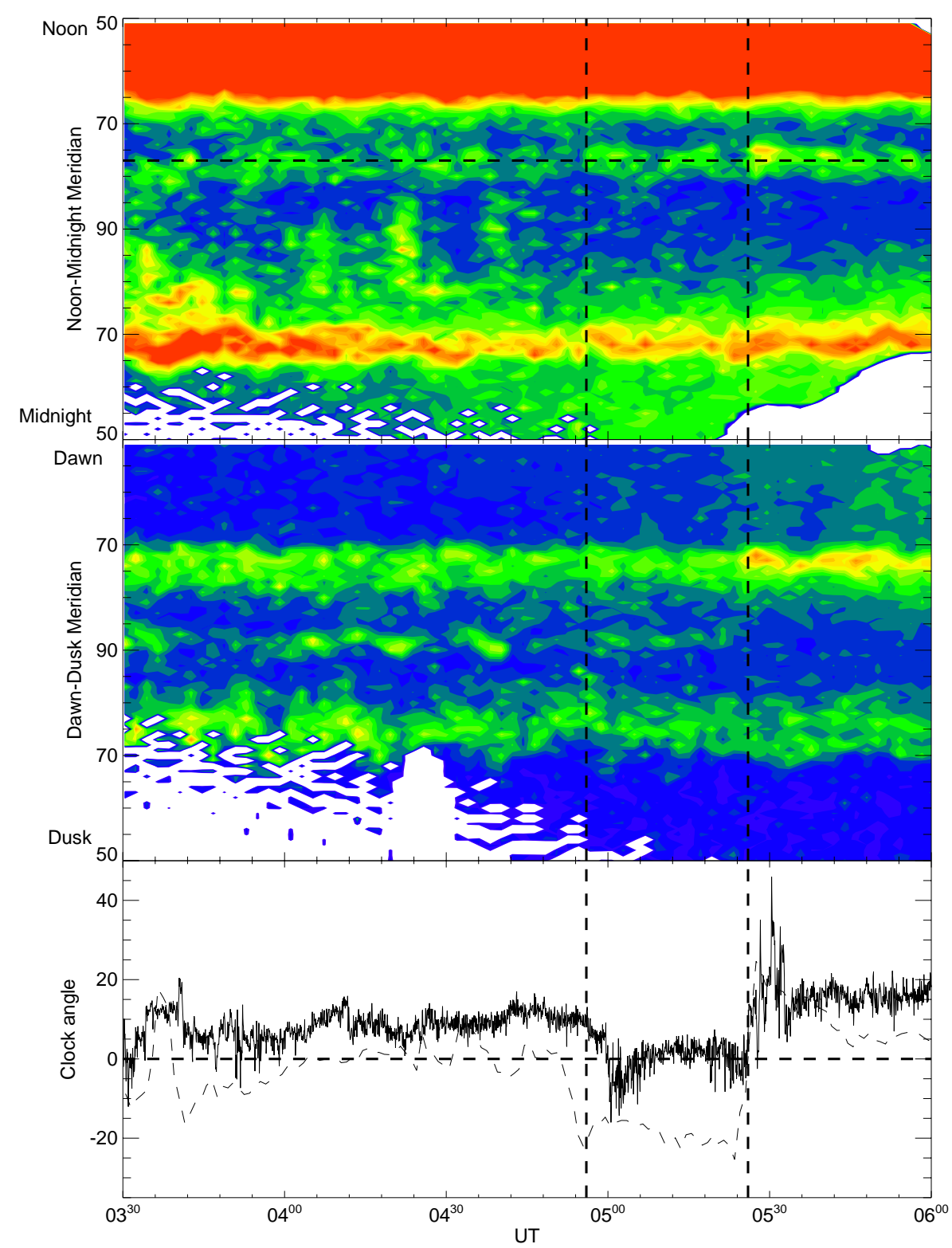

Fig. 4. Noon-midnight and dawn-dusk keograms of the WIC data during the interval of interest, 03:30-06:00 UT on 18 December 2002. In the first panel noon is at the top and midnight at the bottom, in the second, dawn is at the top and dusk at the bottom. These demonstrate that the auroral oval stays at approximately the same latitude throughout. The horizontal dashed line in the noon-midnight keogram represents the latitude of the OCB. Below this is the clock angle measured by Geotail (black line) and Cluster (dashed line).

closed field lines and the higher latitude region of proton aurora as being associated with the cusp on open field lines. In this case we would place the OCB at the equatorward edge of the proton aurora, at $\sim 77^{\circ}$ latitude near noon (represented by the black crosses in Fig. 3). Further supporting evidence for locating the OCB at this latitude will be presented below.

Keograms were generated with cuts from noon to midnight, and dawn to dusk using WIC data (Fig. 4). These clearly show that the auroral oval remains stationary throughout the interval, suggesting that the polar cap is neither ex- panding nor contracting significantly. We note also the clear presence of a transpolar arc near the noon-midnight meridian, evident in the dawn-dusk keogram. The location of the dayside OCB is marked with a horizontal dashed line at $77^{\circ}$ latitude in the noon-midnight keogram.

\subsection{Identifying the open/closed field line boundary}

Identification of the open/closed field line boundary (OCB) is extremely important in determining whether dual lobe 


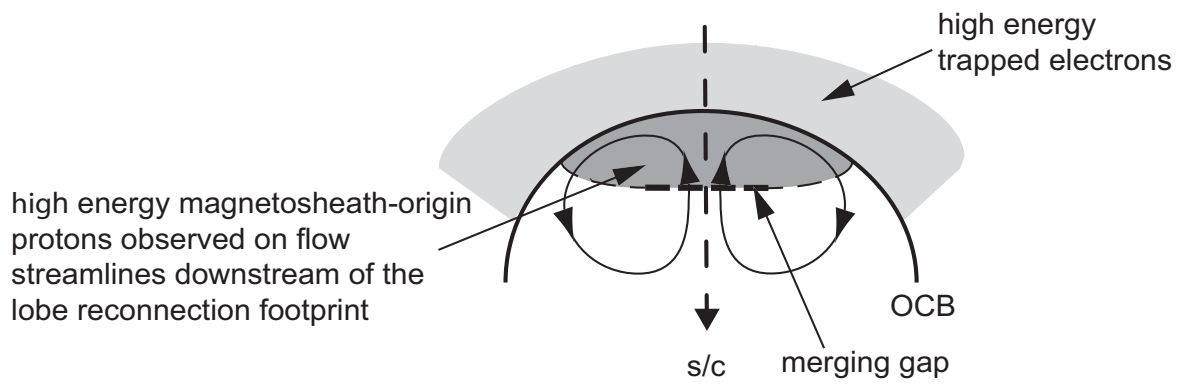

Single lobe reconnection

Fig. 5. A schematic to illustrate the important features and particle populations in the vicinity of the dayside polar cap. Looking down on the northern hemisphere with the Sun to the top of the figure, the solid semi-circle represents the OCB. Field lines that map to within this region are open, whereas those outside it are closed. The thick dashed line within this is the merging gap, which is the ionospheric foorprint of the lobe reconnection site. The thin lines with black arrows are flow streamlines and demonstrate the reverse twin cell convection pattern of single lobe reconnection. The thick vertical dashed line is the trajectory of a poleward moving spacecraft. The light grey shaded area is a region of high energy trapped electrons on closed field lines and the darker grey region represents high energy protons that have travelled down newly-reconnected field lines.

reconnection has taken place. Sunward flow is expected during single and dual lobe reconnection and therefore cannot distinguish between the two processes; only sunward flow across this boundary, representing the closure of open flux, is a signature of dual lobe reconnection.

As a spacecraft traverses the polar cap it will see different particle populations (Fig. 5). When it is within a region of closed field lines at auroral latitudes, it will see high energy electrons that are trapped and mirror between hemispheres without escaping. On open field lines however, any high energy particles will mirror once near the Earth before escaping along the open field line into the magnetotail. Hence, open field lines are usually devoid of high energy particles except where they are being injected into the magnetosphere from the magnetosheath, such as ions in the cusp region, and for this reason the polar cap tends to appear dim in auroral images. A good signature of the OCB would therefore be the sharp transition between high energy trapped electrons and high energy ions as the spacecraft traverses from the noonsector auroral zone into the polar cap (as discussed by e.g. Milan et al., 2003). For lobe reconnection a poleward moving spacecraft would observe a "reverse-dispersed" ion signature (Woch and Lundin, 1992; Øieroset et al., 1997), encountering increasingly higher energy ions as it approaches the merging gap, located some distance poleward of the OCB.

The NOAA 15, 16 and 17 (Evans and Greer, 2000), and FAST (Carlson et al., 1998) spacecraft all passed over the polar cap during the interval. For each spacecraft the electron and proton measurements were plotted, along with the superposition of the footprint of the orbital field lines over a typical WIC image. In this way it was possible to identify the high energy electron/ion boundary with a specific location on Earth, and relative to the aurorae. From Fig. 6 it can be seen that both FAST and the NOAA spacecraft observed a sharp decrease in the flux of high energy electrons polewards of $77^{\circ}$ latitude. In addition FAST sees an increase in the flux of low energy electrons and an increase in the flux of high energy protons poleward of this latitude, the signature of cusp-like precipitation on open field lines. The latitude of the dayside OCB was therefore determined to be $77^{\circ}$, which also corresponds to the equatorward edge of the proton aurora as identified using the IMAGE data (Fig. 3a). This latitude is marked on Fig. 6 by black crosses. No dispersion was observed in the protons as FAST made a longitudinal, not latitudinal, cut through this region.

It is widely acknowledged that open field lines considerably broaden the spectral width of a radar backscatter echo in comparison with closed field lines (e.g. Baker et al., 1995; Milan et al., 1999, 2000; Moen et al., 2001, 2002; Chisham and Freeman, 2003, 2005; Oksavik et al., 2004) and therefore the spectral width of radar backscatter can be used to identify the OCB. The two radars of the CUTLASS array, the Iceland East and Finland radars, part of the SuperDARN network, were in the correct location to observe this backscatter on the dayside. During the interval both radars had good coverage of the dayside polar cap, and the boundary between broad and narrow spectral widths was determined to be $\sim 77^{\circ} \mathrm{mag}$ netic latitude, in agreement with the spacecraft observations described above.

Having previously observed that the size of the polar cap did not significantly change with time during the interval, it is a reasonable assumption that the OCB did not move a significant amount and therefore it is taken as approximately $77^{\circ}$ throughout this analysis. 

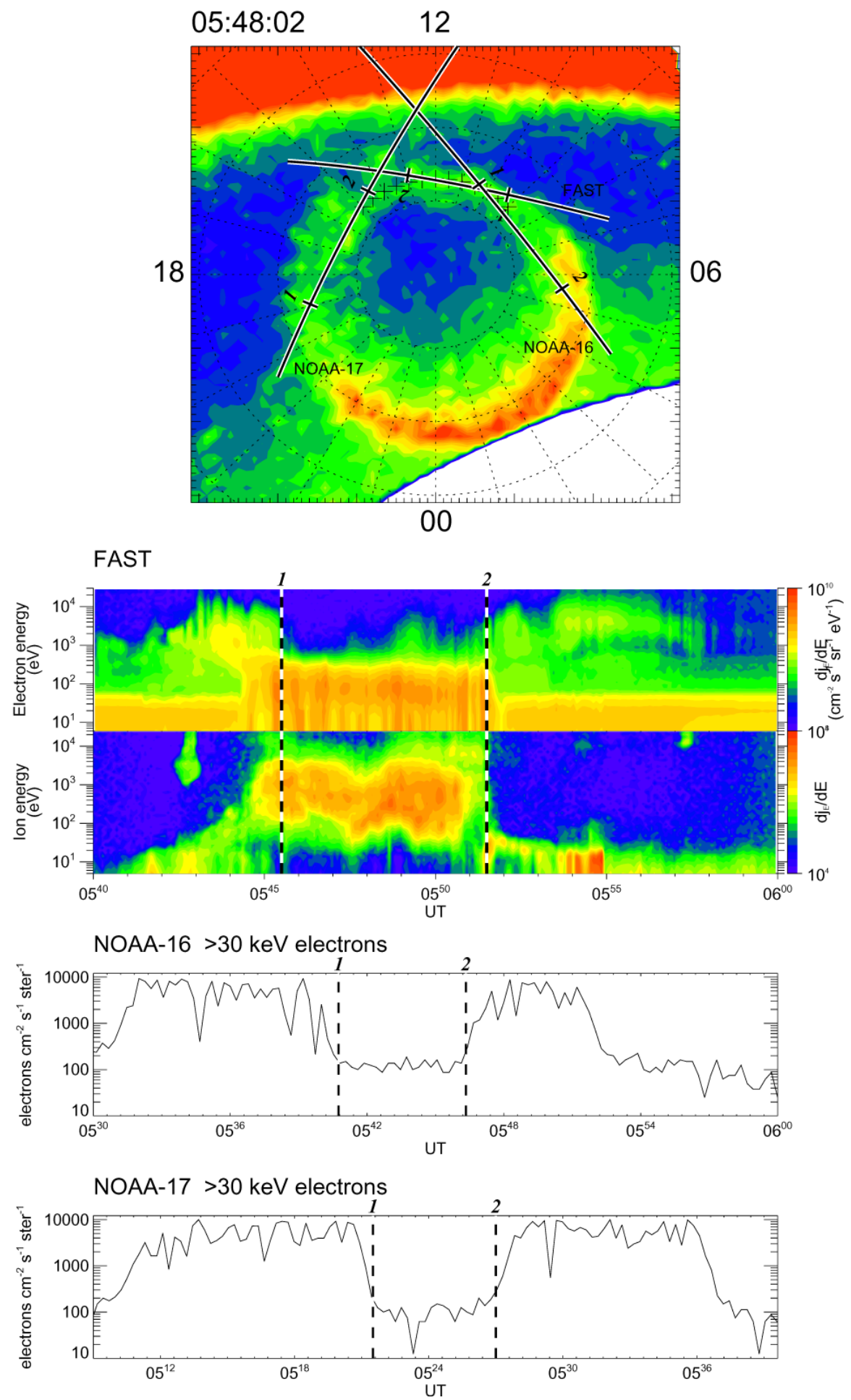

Fig. 6. Spacecraft trajectories during the interval of interest superimposed over a WIC image of the northern polar cap. The location of the OCB is marked by black crosses between 09:00 and 15:00 MLT. Below are the particle data recorded by these spacecraft and used to define the OCB, marked by the vertical dashed lines. 


\subsection{Radar data}

Using the SuperDARN network of radars it is possible to create a map of the electrostatic potential pattern associated with the ionospheric convection over the polar regions (Ruohoniemi and Baker, 1998). This model uses line-of-sight measurements of the ionospheric convection flow from the SuperDARN radar network to constrain a spherical harmonic fit to the electrostatic potential. In regions where observations are sparse, a statistical convection pattern, parameterised by IMF orientation and magnitude, is used to help constrain the fit. For this study the model input was fixed to $B_{Z}>0, B_{Y}=0$ to prevent possible bias by the IMF input and ensure that all changes in the convection pattern are driven by the flow observations. The flow patterns, determined at 2 min cadence, were superimposed over the simultaneous WIC, SI12 and SI13 images. These flow patterns were used to accurately determine the flow in the vicinity of the OCB, $77^{\circ}$ magnetic latitude, marked by the crosses in Fig. 7. During the majority of the interval of study the flow pattern was consistent with the schematic shown in Fig. 1b. That is, sunward flows were seen near noon, but with the reverse cells contained within the open polar cap (Fig. 7a), with only small flows relative to the boundary which we assume are motions of the boundary itself - i.e. we assume that the boundary is adiaroic throughout most of the period. During the period 04:58 to 05:15 UT, however, there is flow observed crossing the location of the OCB (Fig. 7b). Comparing the time of this reconnection burst with the IMF clock angles in Fig. 2, it can be seen that this follows closely after the first of the clock angle turnings through $0^{\circ}$. This, therefore, would be the optimum time for dual lobe reconnection to have occurred. Coupled with our theoretical expectation of flow across the OCB, we interpret this as strong evidence for dual lobe reconnection.

The magnitude of the flow across the boundary provides a measure of the reconnection electric field, which when integrated along the boundary gives the reconnection voltage, that is the rate of transport of magnetic flux from one side of the boundary to the other. When this is integrated over time it gives the flux closed by the dual lobe reconnection. The flow perpendicular to the boundary, and the associated electric field parallel to the boundary were derived directly from the SuperDARN potential maps. The IMF input to the model was fixed such that any changes in the flows were driven solely by the radar data. The electric field and flow were determined every 0.25 hours of MLT between 09:00 and 15:00 MLT at a latitude of $77^{\circ}$, our estimate of the location of the OCB. The time history of the flow between 03:30 and 06:00 UT is shown as a contour plot in Fig. 8, where positive flows are into the polar cap, and negative flows are out of the polar cap. Before 04:55 UT the observed flows are small, in general of order $\pm 50 \mathrm{~m} \mathrm{~s}^{-1}$. Two strong bursts of flow out of the polar cap are seen near noon, at 05:0005:24 UT and 05:30-05:40 UT. These are accompanied by
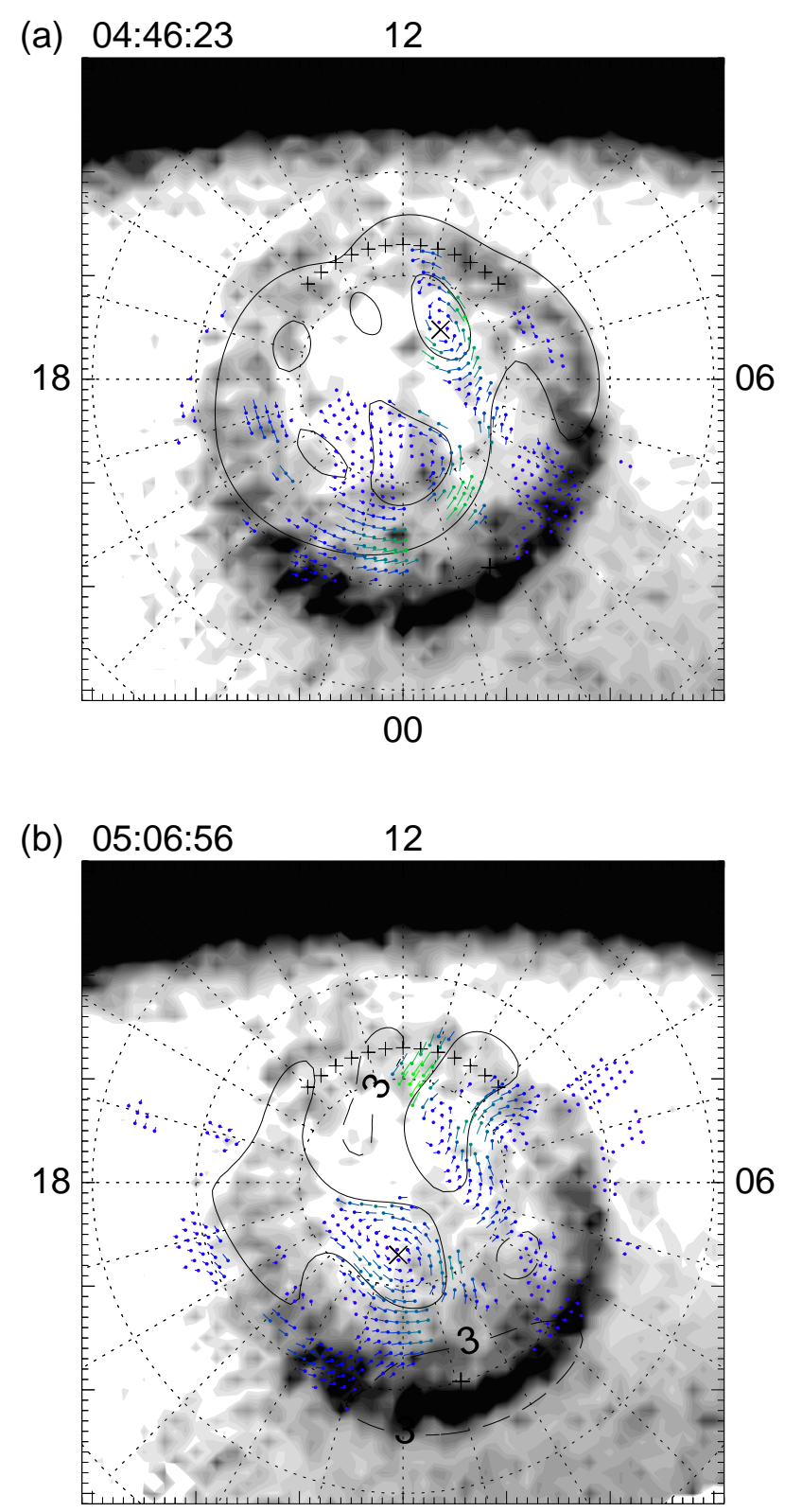

00

Fig. 7. WIC images of the northern polar cap, superimposed over which are the potential contours and flow pattern determined by analysis of SuperDARN radar data. The location of the OCB is marked by the crosses between 09:00 and 15:00 MLT. (a) All flow contained within the polar cap (b) Equatorward flow across the OCB.

weaker poleward flows away from noon. We interpret the equatorward (sunward) flows as plasma flow out of the polar cap along the length of the merging gap due to the closure of the open flux by dual lobe reconnection; the poleward flows are associated with the contraction of the polar cap, along adiaroic portions of the OCB. 


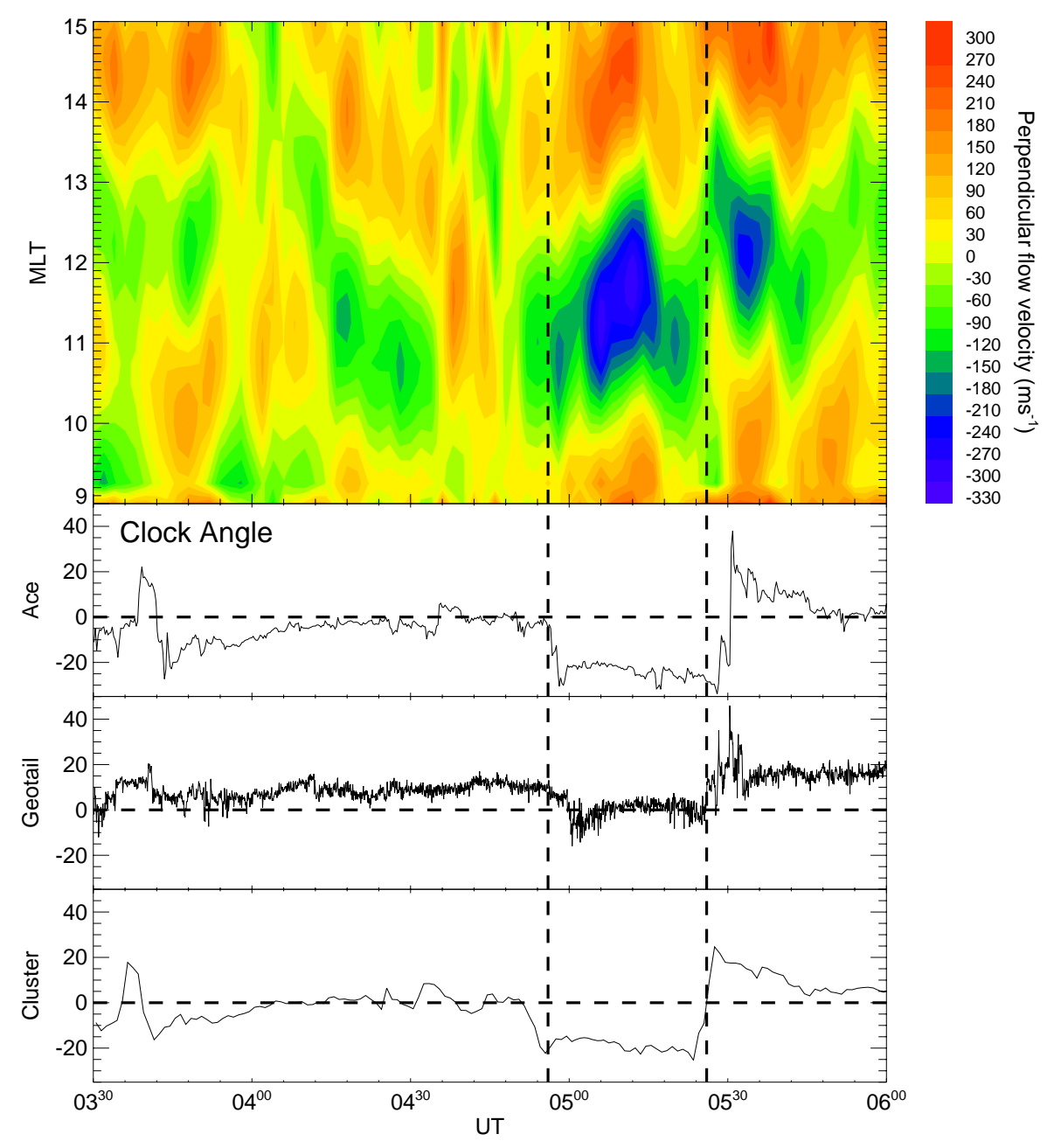

Fig. 8. A contour plot showing the velocity of plasma flow across the OCB, previously determined to be at $77^{\circ}$ magnetic latitude. Blue represents flow equatorward while red represents flow poleward. Two intervals of equatorward flow across the OCB can be clearly identified beginning at 05:00 UT and 05:30 UT. The clock angles from ACE, Geotail and Cluster displayed below show that the start of these flows corresponds to the time when the clock angle passes through zero, represented by vertical dashed lines.

The noon portion of the dayside aurora was analysed for each of the 2 minute WIC images during the $2 \frac{1}{2} 2$ hour interval. The maximum brightness within the box indicated in Fig. 3a was plotted with time in Fig. 3b and it is clear that the brightness peaks at the time of the onset of each burst of reconnection (marked by the vertical dashed lines). Since the IMF is northward throughout the interval, it would be expected that single lobe reconnection is occurring throughout and there will be aurora associated with particles accelerated at the magnetopause. These give the aurora poleward of the OCB and the proton fluxes observed by FAST. We interpret the enhanced luminosity as a contribution of magnetosheath particles injected at the southern lobe reconnection site during dual lobe reconnection increasing the particle flux into the northern hemisphere ionosphere. This, then, is an additional signature of the interconnection of the two hemispheres by dual lobe reconnection.

\subsection{Plasma sheet}

To investigate the effect of dual lobe reconnection on the plasma sheet, the high energy proton density within the inner edge of the plasma sheet was measured by four LANL spacecraft at geosynchronous orbit between 17 and 22 December 2002 (Fig. 9). The plasma density from four spacecraft, located at four geographic locations spaced around the equator, have been superimposed. This gives an indication of the plasma density as the spacecraft sweep through local time; the highest densities are found on the nightside, in the inner edge of the plasma sheet. Prior to our interval of interest the plasma sheet density was $\sim 0.4 \mathrm{~cm}^{-3}$ which is a standard quiet time value (Øieroset et al., 2005). It remained at this density until approximately 00:30 UT on 19 December when it abruptly increased to $\sim 5 \mathrm{~cm}^{-3}$. The density then decreased to a value of $\sim 1 \mathrm{~cm}^{-3}$ over the next $24 \mathrm{~h}$, which was 

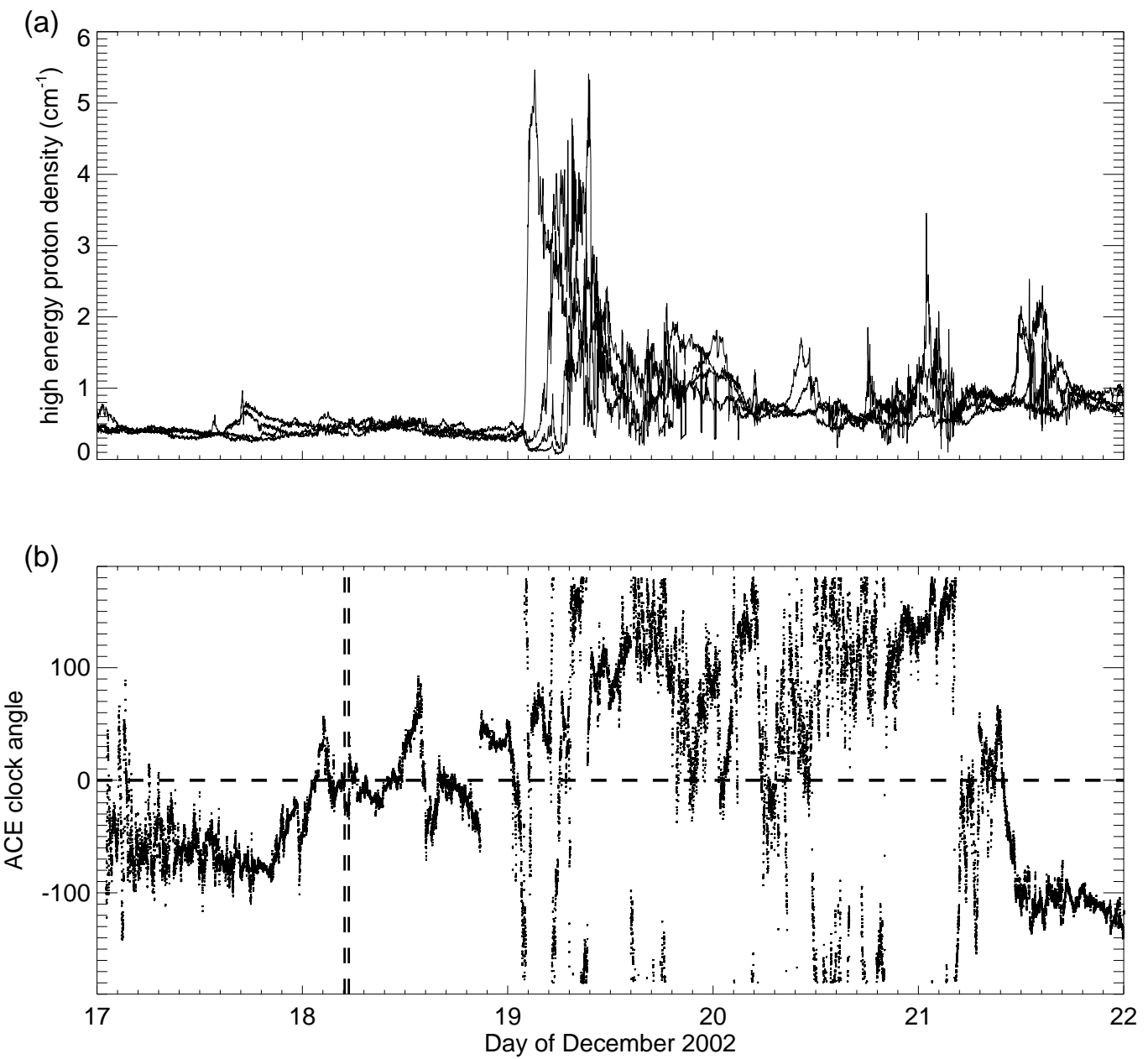

Fig. 9. (a) High energy proton density measured by LANL 1990-095, 1991-080, 1994-084, and LANL-97A in the interval 17-22 December 2002. (b) Clock angle measured by ACE (lagged to the magnetopause). The horizontal dashed line represents $0^{\circ}$ and the vertical dashed lines represent the times at which the clock angle passed through zero.

then maintained for several days. Øieroset et al. (2005) define the threshold density for the cold, dense plasma sheet to be $1-2 \mathrm{~cm}^{-3}$ therefore it is thought that the increase in density observed here is due to the formation of such a plasma sheet; confirmed with observations by FAST (J. P. McFadden, private communication). It is striking that the increase in plasma sheet density appears to occur at approximately the same time as the southward turning of the IMF. It could be that the southward turning (and therefore the onset of low latitude reconnection) increases the rate of transport of cold, dense plasma within the magnetosphere such that it reaches the LANL spacecraft rapidly. The bottom panel in Fig. 9 shows the clock angle from the 17 to the 22 December. The clock angle passes through zero a number of times before and after the two times identified in this study (marked by the vertical dashed lines). These other crossings cannot be studied in as much detail due to a lack of radar and imager data, but it should be noted that dual lobe reconnection would be expected to have occurred at each of these crossings which would contribute more plasma to the cold, dense plasma sheet. We will estimate the plasma capture efficiency of dual lobe reconnection below.

\section{Discussion}

Two specific times were identified from ACE, Cluster and Geotail IMF magnetic field data during which the clock angle appeared to pass through zero and dual lobe reconnection would be expected to occur.

The OCB was determined from radar and spacecraft data. For the spacecraft, the boundary was determined using the sharp transition between high energy electron/ion precipitation seen by the spacecraft as it crossed the noon sector auroral oval and polar cap (Fig. 6). Data taken from NOAA 15, 16 and 17, and FAST are all in agreement that the OCB was 

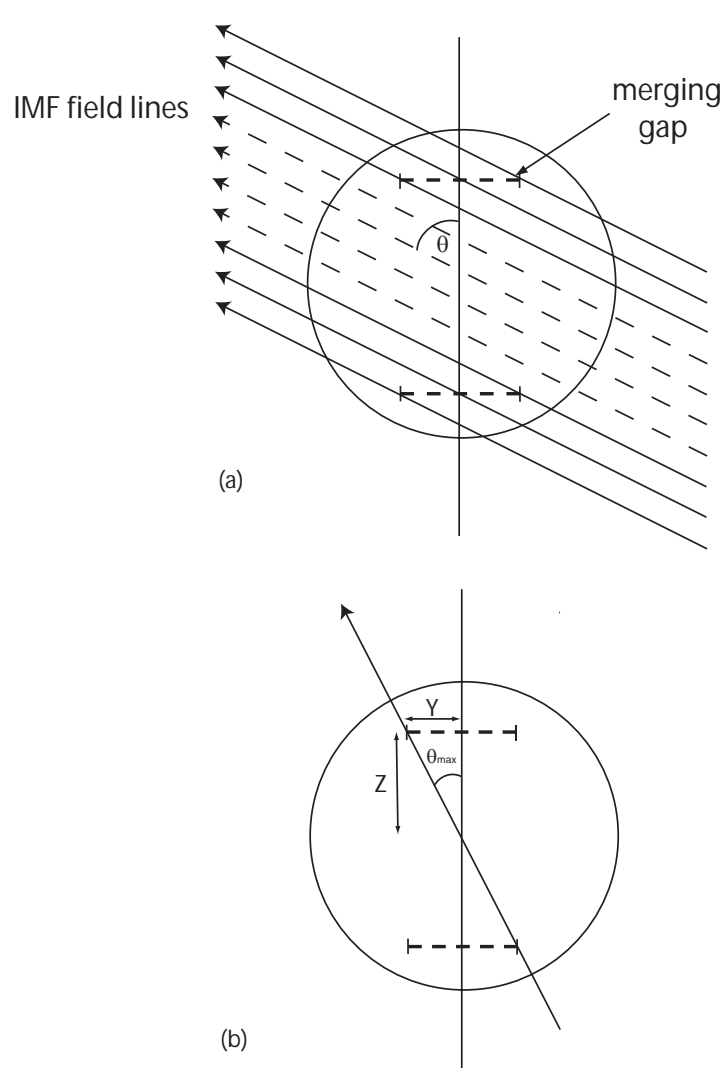

Fig. 10. Schematics to show (a) single lobe reconnection in both hemispheres during northward IMF, and (b) the maximum clock angle for the same IMF field line to reconnect in both hemispheres simultaneously, i.e. dual lobe reconnection to occur.

approximately at $77^{\circ}$ magnetic latitude. Backscatter from the SuperDARN radars demonstrated that the high/low spectral width boundary and therefore the OCB was at $\sim 77^{\circ}$ latitude in agreement with the spacecraft data. This also marked the equatorward edge of the proton aurora near noon, the protons being of magnetosheath origin and associated with open field lines.

Potential maps were created from SuperDARN data and these were converted into flow maps. The velocity of the plasma across the OCB was calculated from the radar data and plotted in Fig. 8. Two clear periods of sunward flow across a $2 \mathrm{~h}$ MLT portion of the OCB are visible and appear to begin exactly at the two times that the clock angle is observed to pass through zero. Single lobe reconnection produces sunward flow but this is contained within the polar cap. We interpret flow across the OCB as strong evidence for the occurrence of dual lobe reconnection and the closure of open magnetic flux at the dayside. Simultaneous anti-sunward flows away from noon are interpreted as a contraction of the polar cap, associated with the closure of open flux.

The clock angle measured by the three upstream spacecraft differs depending on location; however all are close to $0^{\circ}$ and

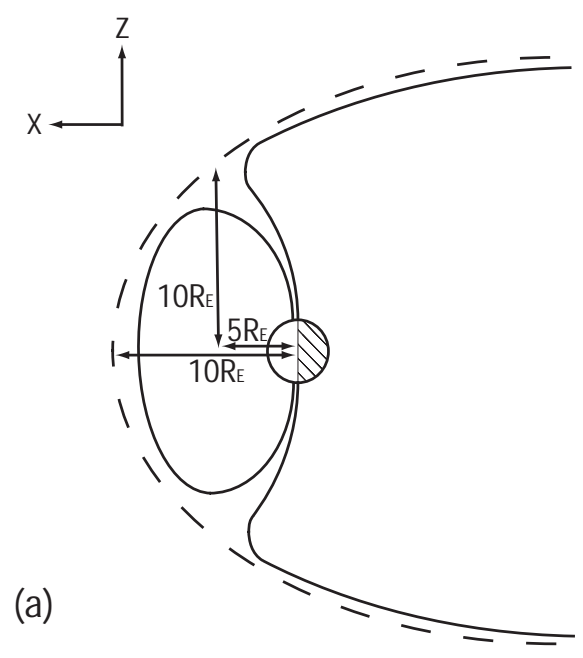

(b)

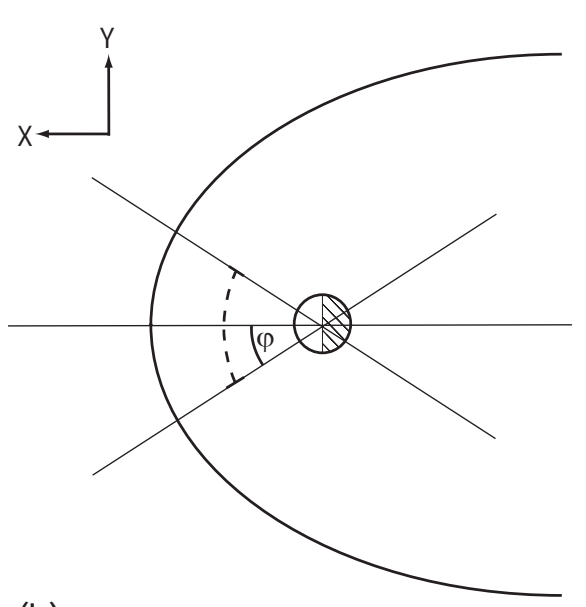

Fig. 11. Schematics to show (a) the estimated position of the reconnection point in the $\mathrm{X}-\mathrm{Z}$ plane, $\mathrm{X}=5 R_{E}, \mathrm{Z}=10 R_{E}$ and (b) the merging gap (dashed line) in the X-Y plane, $\varphi=1 \mathrm{~h}$ MLT.

all show the same variation. Our observation of dual lobe reconnection following the times of the clock angle rotation suggests that at the reconnection sites the clock angle passes through $0^{\circ}$. If this is the case we estimate that the clock angle at the reconnection sites can be no larger than $\pm 10^{\circ}$ at other times. This puts a constraint on the range of clock angles for which dual lobe reconnection can occur, which we suggest is $|\theta|<10^{\circ}$. We can also estimate this from the geometry at the magnetopause.

Figure 10a is a schematic showing the front of the magnetosphere looking from the Sun, to demonstrate how single lobe reconnection can occur simultaneously in both hemispheres during periods of northward IMF. The solid lines of IMF are those reconnecting at the merging gaps, shown by horizontal dashed lines. Figure 10b shows the limiting case, i.e. the maximum clock angle for which a single field line can 
undergo dual lobe reconnection. From the dimensions of the two bursts of flow identified in Fig. 8, we conclude that the merging gaps are approximately $2 \mathrm{~h}$ of MLT in length. Assuming that the reconnection point is at $\mathrm{Z}= \pm 10 R_{E}, \mathrm{X}=5 R_{E}$ (Fig. 11), the length of each merging gap can be calculated to be approximately $2.6 R_{E}$ in Y. From this we can determine $\theta_{\max }$ (Fig. 10b) to be approximately $8^{\circ}$, in excellent agreement with the estimate of $|\theta| \leq 10^{\circ}$ made by comparing the time of the onset of reconnection with the IMF clock angles.

The bursts of sunward flow observed at 05:00 UT and 05:30 UT in Fig. 8 have durations of approximately 25 and $10 \mathrm{~min}$, respectively. The duration of each represents the time taken for the magnetosphere to reconfigure following an interval of dual lobe reconnection; we assume that reconnection occurred for the relatively short period of time that the clock angle passed through $0^{\circ}$, also the duration of the luminosity enhancements at these times (Fig. 3). These times are therefore in agreement with Cowley and Lockwood (1992) who suggested that the magnetosphere takes approximately 15 min to re-adjust following a perturbation away from equilibrium.

The total flux crossing the OCB during each interval can be calculated from the SuperDARN potential maps by integrating the potential along the boundary with respect to time. This was found to be $9.1 \times 10^{6} \mathrm{~Wb}$ for the period 05:0005:24 UT and $3.2 \times 10^{6} \mathrm{~Wb}$ for the period 05:30-05:40 UT. As a percentage of the total flux within the polar cap (calculated to be approximately $0.5 \mathrm{GWb}$ in total), these are approximately 1.8 and $0.6 \%$ and therefore we conclude that dual lobe reconnection closes only a small amount of flux during this interval. Clearly the clock angle would have to remain near $0^{\circ}$ for long periods of time for significant flux closure to occur. Given the total amount of flux closed and assuming that the OCB remains circular, the poleward motion of the OCB would be $\sim 0.15^{\circ}$ magnetic latitude during the interval. It is not surprising therefore that it is not possible to identify this contraction in the keograms in Fig. 4.

We cannot measure the flux closure rates for the two events directly as we measure the flux transport in response to the magnetospheric reconfiguration, which occurs over a longer timescale than the reconnection itself. However, if reconnection during the first burst is assumed to occur for $4 \mathrm{~min}$, the approximate duration of the clock angle rotation, then we can estimate a flux closure rate of $\sim 35 \mathrm{kV}$.

It is possible to place an upper limit on the number of particles captured by the magnetosphere during these intervals of dual lobe reconnection by estimating the amount of solar wind plasma on the interplanetary field lines that reconnected in both hemispheres. Given the magnetic flux closed during the reconnection, it is possible to calculate the volume of the upstream solar wind that contains this amount of flux. Then knowing the density of the solar wind from the upstream measurements made by ACE it is possible to calculate the number of particles captured during the interval. The total magnetic flux closed during both bursts of reconnec- tion was calculated earlier to be $\sim 1.2 \times 10^{7} \mathrm{~Wb}$. The equatorial cross-sectional area of the upstream volume containing $\sim 1.2 \times 10^{7} \mathrm{~Wb}$ of magnetic flux is given by $\mathrm{A}=\mathrm{F} / \mathrm{B}$ where $\mathrm{F}$ is the flux closed and $\mathrm{B}$ is the average $B_{Z}$ component of the IMF ( $\sim 10 \mathrm{nT})$. The GSM $Z$ dimension of this volume is given by the distance between the two cusps, here estimated to be $\sim 20 R_{E}$. Given that the upstream proton number density is measured by ACE to be $16 \mathrm{~cm}^{-3}$ at this time, the number of ions captured is of the order of $2.5 \times 10^{30}$ representing a mass of approximately 4 tonnes of protons. We stress that this represents an upper limit in which it is assumed that no plasma is lost by mirroring in the near-Earth magnetic field after reconnection has taken place in one hemisphere but before field lines become closed by reconnection in the other hemisphere. We also have not accounted for the formation of a plasma depletion layer near the subsolar magnetopause.

To assess the implications of this plasma capture for the magnetotail and plasma sheet we can imagine transferring this plasma into the tail to determine its contribution to the pre-existing plasma content. Estimating the plasma sheet dimensions to be $50 R_{E}, 35 R_{E}$ and $5 R_{E}$ in $\mathrm{X}, \mathrm{Y}$ and $\mathrm{Z}$, the density of the plasma sheet would increase by $\sim 1 \mathrm{~cm}^{-3}$. This demonstrates that dual lobe reconnection could be an extremely efficient method of populating the plasma sheet.

The plasma data from the LANL spacecraft passing through the plasma sheet indicates that a dense plasma sheet appears to have been detected following this interval of dual lobe reconnection, at approximately 02:00 UT on 19 December (Fig. 9). The density of the plasma sheet will not increase immediately following the plasma capture on the dayside. The mass loaded field lines must migrate to the tail and the plasma be distributed through the plasma sheet. Clearly the newly-closed field lines must remain closed during this migration; if the IMF were to turn southward shortly after the plasma capture the field lines could be reopened and the plasma lost. Hence we expect that a cold dense plasma sheet requires long periods of northwards IMF to be formed, even if dual lobe reconnection occurs for only a small fraction of this time. The IMF was observed by ACE to be northward until 00:32 UT on 19 December, approximately $19 \mathrm{~h}$ after the second interval of dual lobe reconnection (Fig. 9). Following the initial increase in the near-Earth plasma sheet density to $\sim 5 \mathrm{~cm}^{-3}$ at 02:00 UT on 19 December, the density then decays to $\sim 1 \mathrm{~cm}^{-3}$ at approximately 05:00 UT which represents an overall increase in density of $0.5 \mathrm{~cm}^{-3}$. This is in good agreement with our predicted plasma sheet density increase of $1 \mathrm{~cm}^{-3}$ from the number of upstream particles captured by reconnection. The decay from $5 \mathrm{~cm}^{-3}$ to $1 \mathrm{~cm}^{-3}$ might indicate that plasma first enters the plasma sheet near the Earth before being distributed more evenly throughout the tail. This decay could also be explained by loss processes including precipitation into the ionosphere and loss down the tail due to substorms, or more gradual loss processes which could deposit particles into the ionosphere (e.g. Oksavik et al., 2006). 


\section{Conclusions}

We have presented the first substantial evidence for dual lobe reconnection from ionospheric flows and auroral signatures. Strongly northward IMF with a clock angle close to $0^{\circ}$ provides the necessary conditions for this process. The specific signature identifying dual as opposed to single lobe reconnection is sunward flows across the noon portion of the OCB. These were observed in the SuperDARN radar data. The OCB is identified by the high energy electron/ion precipitation boundary observed from spacecraft, from radar backscatter, and auroral observations. Two separate intervals of sunward flow across the OCB are identified (Fig. 8) and these are associated with the reconfiguration of the magnetosphere in response to two bursts of dual lobe reconnection occurring at rotations of the IMF through $0^{\circ}$ clock angle.

From this study we conclude that: (1) Dual lobe reconnection does occur under conditions of strongly northward IMF; (2) In order for this process to take place the clock angle must be within $\pm 10^{\circ}$ of zero; (3) The total flux crossing the OCB during each burst is small; (4) The flux closure rates observed enable a rough calculation of the number of particles captured during reconnection. This suggests that sufficient particles were captured to populate the cold, dense plasma sheet observed in subsequent hours, despite the fact that dual lobe reconnection only occurred for a few minutes.

Other periods of dual lobe reconnection are currently being analysed, the most significant of which is believed to have closed $\sim 10 \%$ of the flux in the polar cap.

Acknowledgements. S. Imber is supported by a PPARC studentship. B. Hubert is supported by the Belgian National Fund for Scientific Research (FNRS) and his work was supported by the PRODEX program of the European Space Agency (ESA). We would like to thank CDAWeb and the National Geophysical Data Center for access to many data sets. We would also like to thank the principal investigators of all the other instruments used in this study; N. F. Ness at Bartol Research Institute and D. J. McComas at Southwest Research Institute for ACE MFI and SWE data, E. A. Lucek at Imperial College, London for the Cluster FGM data, C. Carlson for the FAST data, S. B. Mende of the University of California, Berkeley for the IMAGE FUV data, R. Bushnell for the NOAA-16 and NOAA-17 SEM-2 data and R. Belian for the LANL SOPA data. We would also like to thank all of the principal investigators of the SuperDARN radars.

Topical Editor I. A. Daglis thanks K. Oksavik and another referee for their help in evaluating this paper.

\section{References}

Baker, K. B., Dudeney, J. R., Greenwald, R. A., Pinnock, M., Newell, P. T., Rodger, A. S., Mattin, N., and Meng, C.-I.: HF radar signatures of the cusp and low-latitude boundary layer, J. Geophys. Res., 100, 7671-7695, 1995.

Balogh, A., Dunlop, M. W., Cowley, S. W. H., Southwood, D. J., Thomlinson, J. G., Glassmeier, K. H., Musmann, G., Luhr, H., Buchert, S., Acuna, M. H., Fairfield, D. H., Slavin, J. A.,
Riedler, W., Schwingenschuch, K., and Kivelson, M. G.: The cluster magnetic field investigation, Space Sci. Rev., 79, 65-91, 1997.

Belian, R. D., Gisler, G. R., Cayton, T., and Christensen, R.: High $\mathrm{Z}$ energetic particles at geosynchronous orbit during the great solar proton event of October 1989, J. Geophys. Res., 97, 16897$16906,1992$.

Carlson, C. W., Pfaff, R. F., and Watzin, J. G.: The Fast Auroral Snapshot mission, Geophys. Res. Lett., 25, 2013-2016, 1998.

Chisham, G. and Freeman, M. P.: A technique for accurately determining the cusp-region polar cap boundary using SuperDARN HF radar measurements, Annales Geophysicae, 21, 983-996, 2003.

Chisham, G., Freeman, M. P., Sotirelis, T., Greenwald, R. A., Lester, M., and Villain, J.-P., A statistical comparison of SuperDARN spectral width boundaries and DMSP particle precipitation boundaries in the morning sector ionosphere, Ann. Geophys., 23, 733-743, 2005, http://www.ann-geophys.net/23/733/2005/.

Cowley, S. W. H.: Magnetospheric and ionospheric flow and the interplanetary magnetic field, The Physical Basis of the Ionosphere in the Solar-Terrestrial System, AGARD Conf. Publ., AGARDCP-295, 4/1-4/14, 1981.

Cowley, S. W. H.: Interpretation of observed relations between solar wind characteristics and effects at ionospheric altitudes, in: High Latitude Space Plasma Physics, edited by: Hultqvist, B. and Hagfors, T., Plenum, New York, 225-249, 1983.

Cowley, S. W. H. and Lockwood, M.: Excitation and decay of solar wind-driven flows in the magnetosphere-ionosphere system, Ann. Geophys., 10, 103-115, 1992, http://www.ann-geophys.net/10/103/1992/.

Crooker, N. U.: Reverse Convection, J. Geophys. Res., 97, 1936319372, 1992.

Dungey, J. W.: Interplanetary magnetic field and the auroral zones, Phys. Rev. Letters, 6, 47-48, 1961.

Dungey, J. W.: The structure of the ionosphere, or adventures in velocity space, in: Geophysics: The Earth's Environment, edited by: DeWitt, C., Hiebolt, J., and Lebeau, A., Gordon and Breach, New York, 526-536, 1963.

Escoubet, C. P., Fehringer, M., and Goldstein, M.: The Cluster mission - Introduction, Ann. Geophys., 19, 1197-1200, 2001, http://www.ann-geophys.net/19/1197/2001/.

Evans, D. S. and Greer, M. S.: Polar orbiting environmental satellite space environment monitor - 2: Instrument descriptions and archive data documentation, NOAA Technical Memorandum OAR SEC-93, Space Environment Center, Boulder, Colorado, 2000.

Greenwald, R. A., Baker, K. B., Dudeney, J. R., Pinnock, M., Jones, T. B., Thomas, E. C., Villain, J.-P., Cerisier, J.-C., Senior, C., Hanuise, C., Hunsucker, R. D., Sofko, G., Koehler, J., Nielsen, E., Pellinen, R., Walker, A. D. M., Sato, N., and Yamagishi, H.: DARN/SuperDARN: a global view of the dynamics of highlatitude convection, Space Sci. Rev., 71, 761-796, 1995.

Huang, C., Sofko, G. J., Koustov, A. V, Andre, D. A., Ruohoniemi, J. M., Greenwald, R. A., and Hairston, M. R.: Evolution of ionospheric multicell convection during Northward interplanetary magnetic field with $\left|\mathrm{B}_{z} / \mathrm{B}_{y}\right|>1$, J. Geophys. Res., 108, 27 095-27 107, 2000.

Kokubun, S., Yamamoto, T., Acuña, M. H., Hayashi, K., Shiokawa, 
K., and Kawano, H., The GEOTAIL magnetic field experiment, J. Geomagn. Geoelectr., 46, 7-21, 1994.

McComas, D. J., Blame, S. J., Barker, P., Feldman, W. C., Phillips, J. L., Riley, P., and Griffee, J. W.: Solar Wind Electron Proton Alpha Monitor (SWEPAM) for the Advanced Composition Explorer, Space Science Reviews, 86, 563-612, 1998.

Mende, S. B., Heetderks, H., Frey, H. U., Lampton, M., Geller, S. P., Habraken, S., Renotte, E., Jamar, C., Rochus, P., Spann, J., Fuselier, S. A., Gerard, J.-C., Gladstone, R., Murphree, S., and Cogger, L.: Far ultraviolet imaging from the IMAGE spacecraft, 1. System design, Space Science Reviews, 91, 243-270, 2000.

Mende, S. B., Heetderks, H., Frey, H. U., Lampton, M., Geller, S. P., Abiad, R., Siegmund, O. H. W., Tremsin, A. S., Spann, J., Dougani, H., Fuselier, S. A., Magoncelli, A. L., Bumala, M. B., Murphree, S., and Trondsen, T.: Far ultraviolet imaging from the IMAGE spacecraft, 2. Wideband FUV imaging, Space Science Reviews, 91, 271-285, 2000.

Milan, S. E., Lester, M., Cowley, S. W. H., Moen, J., Sandholt, P. E., and Owen, C. J.: Meridian-scanning photometer, coherent HF radar, and magnetometer observations of the cusp: a case study, Ann. Geophys., 17, 159-172, 1999, http://www.ann-geophys.net/17/159/1999/.

Milan, S. E., Lester, M., Cowley, S. W. H., and Brittnacher, M.: Dayside convection and auroral morphology during an interval of Northward interplanetary magnetic field, J. Geophys. Res., 105, 15 741-15 755, 2000.

Milan, S. E., Lester, M., Cowley, S. W. H. , Oksavik, K., Brittnacher, M., Greenwald, R. A., Sofko, G., and Villain, J.-P.: Variations in polar cap area during two substorm cycles, Ann. Geophys., 21, 1121-1140, 2003,

http://www.ann-geophys.net/21/1121/2003/.

Moen, J., Carlson, H. C., Milan, S. E., Shumilov, N., Lybekk, B., Sandholt, P. E., and Lester, M.: On the Collocation between dayside auroral activity and coherent HF radar backscatter, Ann. Geophys., 18, 1531-1549, 2001, http://www.ann-geophys.net/18/1531/2001/.

Moen, J., Walker, I. K., Kersley, L., and Milan, S. E.: On the generation of cusp HF-backscatter irregularities, J. Geophys. Res., 107(A4), 1044, doi:10.1029/2001JA000111, 2002.

Øieroset, M., Sandholt, P. E., Denig, W. F., and Cowley, S. W. H.: Northward interplanetary magnetic field cusp aurora and highlatitude magnetopause reconnection, J. Geophys. Res., 102(A6), $11349-11362,1997$.
Øieroset, M., Raeder, J., Phan, T. D., Wing, S., McFadden, J. P., Li, W., Fujimoto, M., Rème, H., and Balogh, A.: Global cooling and densification of the plasma sheet during an extended period of purely Northward IMF on October 22-24, 2003, Geophys. Res. Lett., 32, L12S07, 2005.

Oksavik, K., Søraas, F., Moen, J., Pfaff, R., Davies, J. A., and Lester, M.: Simultaneous optical, CUTLASS HF radar, and FAST spacecraft observations: Signatures of boundary layer processes in the cusp, Ann. Geophys., 22 511-525, 2004.

Oksavik, K., Rouhoniemi, J. M., Greenwald, R. A., Baker, J. B. H., Moen, J., Carlson, C., Yeoman, T. K., and Lester, M.: Observations of isolated polar cap patches by the European Incoherent Scatter (EISCAT) Svalbard and Super Dual Auroral Radar Network (SuperDARN) Finland radars, J. Geophys. Res., 111(A5), A05310, doi:10.1029/2001JA011400, 2006.

Østgaard, N., Mende., S. B., Frey, H. U., and Sigwarth, J. B.: Simultaneous imaging of the reconnection spot in the opposite hemispheres during Northward IMF, Geophys. Res. Lett., 32, L21104 2005.

Reiff, P. H. and Burch, J. L.: IMF By-dependent plasma flow and Birkeland currents in the dayside magnetosphere: 2. A global model for Northward and southward IMF, J. Geophys. Res., 90, 1595-1609, 1985.

Ruohoniemi, J. M. and Baker, K. B.: Large-scale imaging of highlatitude convection with Super Dual Auroral Radar Network HF radar observations, J. Geophys. Res., 103, 20 797-20 811, 1998.

Russell, C. T.: The configuration of the magnetosphere, in: Critical Problems of Magnetospheric Physics, edited by: Dyer, E. R., Inter-Union Comm. on Sol. Terr. Phys., Natl. Acad. of Sci., Washington, D.C., 1972.

Sandholt, P. E., Farrugia, C. J., Cowley, S. W. H., Denig, W. F., Lester, M., Moen, J., and Lybekk, B.: Capture of magnetosheath plasma by the magnetosphere during Northward IMF, Geophys. Res. Lett., 26, 2833-2836, 1999.

Siscoe, G. L. and Huang, T. S.: Polar cap inflation and deflation, Geophys. Res. Lett., 90, 543-547, 1985.

Smith, C. W., Acuna, M. H., Burlaga, L. F., L'Heureux, J., Ness, N. F., and Scheifele, J.: The ACE Magnetic Fields Experiment, Space Science Reviews, 86, 611-632, 1998.

Stone, E. C., Frandsen, A. M., Mewaldt, R. A., Christian, E. R., Margolies, D., Ormes, J. F., and Snow, F.: The Advanced Composition Explorer, Space Science Reviews, Vol 86, 1-22, 1998.

Woch, J. and Lundin, R.: Magnetosheath plasma precipitation in the polar cusp and its control by the interplanetary magnetic field, J. Geophys. Res., 97, 1421-1430, 1992. 